\title{
O USO DAS TECNOLOGIAS DIGITAIS EM PROL DA APRENDIZAGEM ESCOLAR
}

\author{
THE USE OF DIGITAL TECHNOLOGIES FOR SCHOOL LEARNING
}

\author{
APROXIMACIONES TEORICO-CONCEITUALES DE LOS \\ DERECHOS HUMANOS
}

\author{
Bruno Freitas Santos ${ }^{1}$
}

\begin{abstract}
RESUMO
Este trabalho apresenta a importância da tecnologias digitais em prol de uma aprendizagem escolar, muito mais significativa. Buscou verificar que a educação do futuro começa pela inserção correta de tosos os aparatos tecnológicos que são uteis para o processo de ensino e aprendizagem. Assim, o uso de Tecnologias Digitais de Informação e Comunicação são recursos importantíssimos para tornar as disciplinas escolares do currículo muito mais dinâmicas e enriquecedoras, combatendo de forma mais eficiente os muitos problemas e dificuldades encontradas dentro do processo escolar. $\mathrm{O}$ desenvolvimento de competências e habilidades voltadas para o universo digital é hoje uma das grandes exigências do mercado de trabalho, cabendo a escolar estar apta para ofertar esse tipo de desenvolvimento. As abordagens teóricas aqui tratadas mostraram que as mudança no sistema de ensino ocorreram de forma veloz, e que novas atitudes e uma nova postura desse educador dever tomada e construída. Para que passo a passo o cenário do novo ensino e aprendizagem seja compatível com a era digital em que todos estamos inseridos vivemos.
\end{abstract}

PALAVRAS-CHAVE: Formação. Teorias educacionais. Tecnologias Digitais.

\begin{abstract}
This work presents the importance of digital technologies in favor of a school learning, much more significant. It sought to verify that the education of the future begins by the correct insertion of technological devices that are useful for the teaching and learning process. Thus, the use of Digital Information and Communication Technologies are very important resources to make school curricula much more dynamic and enriching, combating more efficiently the many problems and difficulties encountered within the school process. The development of skills and abilities aimed at the digital universe is today one of the great demands of the labor market, being the school being able to offer this type of development. The theoretical approaches discussed here showed that changes in the educational system occurred quickly, and that new attitudes and a new posture of this educator should be taken and constructed. So that step by step the scenario of new teaching and learning is compatible with the digital age in which we are all inserted we live.
\end{abstract}

KEYWORDS: Training. Educational Theories. Digital Technologies.

\section{RESUMEN}

Este trabajo presenta la importancia de las tecnologías digitales en pro de un aprendizaje escolar, mucho más significativo. Buscó verificar que la educación del futuro comienza por la inserción correcta de tosos

\footnotetext{
${ }^{1}$ brunofreitas2017@ outlook.com.br
}

\begin{tabular}{l|l|r} 
Recebido em: 10/04/2019 & Aceito em: 28/04/2019 & Pg. 115 - 129
\end{tabular}




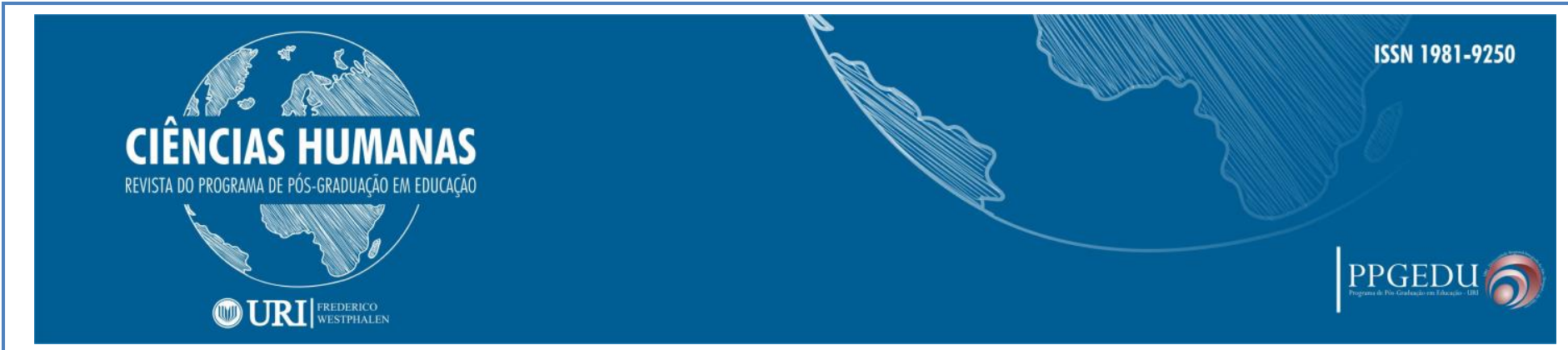

los aparatos tecnológicos que son útiles para el proceso de enseñanza y aprendizaje. Así, el uso de Tecnologías Digitales de Información y Comunicación son recursos importantísimos para hacer las disciplinas escolares del currículo mucho más dinámicas y enriquecedoras, combatiendo de forma más eficiente los muchos problemas y dificultades encontradas dentro del proceso escolar. El desarrollo de competencias y habilidades dirigidas al universo digital es hoy una de las grandes exigencias del mercado de trabajo, cabiendo la escolaridad apta para ofrecer este tipo de desarrollo. Los abordajes teóricos aquí tratados mostraron que los cambios en el sistema de enseñanza ocurrieron de forma veloz, y que nuevas actitudes y una nueva postura de ese educador debida y construida. Para que paso a paso el escenario de la nueva enseñanza y aprendizaje sea compatible con la era digital en que todos estamos insertos vivimos.

PALABRAS CLAVE: Formación. Teorías educativas. Tecnologías Digitales.

\section{INTRODUÇÃO}

Este artigo traz os resultados iniciais de uma pesquisa bibliográficas, que buscou identificar a importância das novas TICs para o processo de escolarização. O uso de Tecnologias Digitais de Informação e Comunicação (TDIC) tem sido um dos caminhos apontado, por inúmeras especialistas como parte da solução, para amenizar muitos problemas presentes na educação atual.

A utilização dos aparatos tecnológicos em sala de aula tem sido significativo e com resultados satisfatórios. Porque por meio deles, crianças, adolescentes e jovens interagem melhor, uma vez que a era digital em que estamos inseridos, é um processo continuo. E sem falar que todos os países, que já adotaram de forma legal as TICs no processo escolar têm mostrado bons resultados, no que se refere a aceitação dos conteúdos didáticos, obtendo de uma melhor compreensão e absorção na aprendizagem. E sem contar no prazer que é aguçado em estudar.

A interação com os recursos tecnológicos são amplos e positivos. Tornando o aprendizado mais lúdico e próximo do contexto em que os alunos vivem. Afinal, de contas sempre ouvimos o discurso de que a aprendizagem escolar, sempre deve ser compatível com a realidade inserida dos alunos.

Assim, o papel do professor, como mediador em sala de aula é imprescindível para que seja introduzidas com planejamento e objetividade cada recurso tecnológico. $\mathrm{O}$ ato de ensinar e aprender no mundo digital é algo desafiador, porém necessário para uma educação muito mais equitativa e significativa.

Diante do exposto, a situação problemas que nortearam este trabalho foram as seguintes: Como ensinar de forma significativa por meios dos recursos

\begin{tabular}{l|l|l} 
Recebido em: 10/04/2019 & Aceito em: 28/04/2019 & Pg. 115 - 129 \\
\hline
\end{tabular}




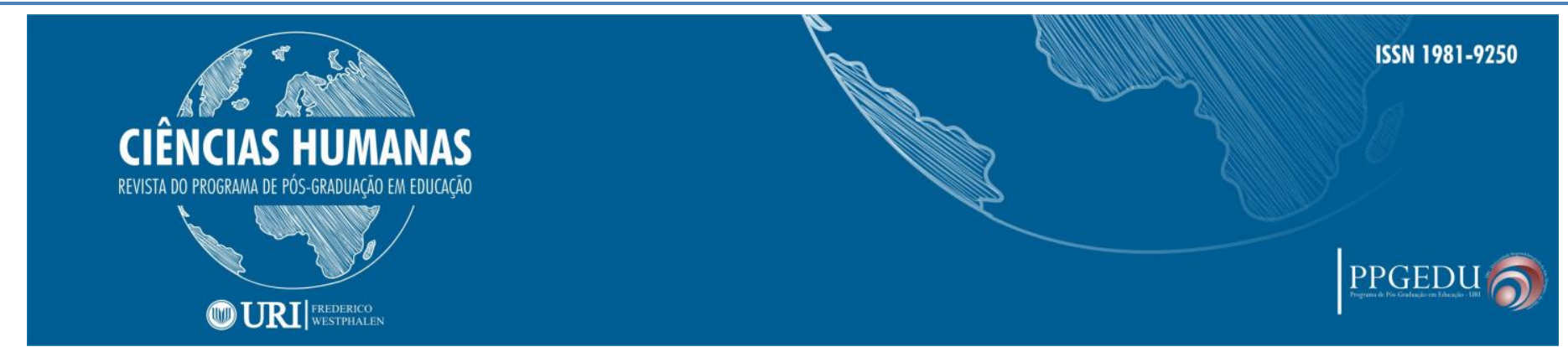

digitais? Quais os recursos e atividades que serão capazes de construir um aprendizado digital. Fundamentado nisso, surge à necessidade de estar sempre inovando e se reinventando dentro do processo de ensino aprendizagem, visando alcançar objetivos cada vez maiores.

Assim, o objetivo do presente artigo é refletir sobre a relevância das tecnologias digitais para os avanços do processo escolar. A justificativa que impulsionou a elaboração desse artigo é a busca por estratégias que possibilitasse um aprender digital mais acessível e significativo sobre a temática aqui discutida. A estrutura desse trabalho se dá por meio de uma apresentação dos posicionamento de alguns teóricos acerca das tecnologias digitais, mostrando os pontos convergentes e divergentes.

\section{METODOLOGIA}

Conforme foi apresentado na Introdução, a pesquisa é bibliográfica, na qual teve como objetivo analisar a importância das novas tecnologias digitais em prol de uma aprendizagem muito mais ampla. Trata-se de uma pesquisa qualitativa e investigativa, realizada no período de trinta dias, onde foram levantadas diferentes posicionamentos acerca da TICs. Quanto a análise dos dados coletados, foram colhidas informações pertinentes, para melhor fundamentar a pesquisa.

\section{RESULTADOS E DISCUSSÕES}

\section{DESTRINCHANDO A TEMÁTICA}

A educação na atualidade requer um novo ajuste, no que se refere a aprendizagem escolar, principalmente para a geração atual, no qual nasceu dentro de um berço tecnológico, repleto de inúmeras informações por todas as partes. Como confirma "Estou conectado, logo existo" (CASTRO, 2013). Nesse sentido o uso das tecnologias

\begin{tabular}{l|l|l} 
Recebido em: 10/04/2019 & Aceito em: 28/04/2019 & Pg. 115 - 129
\end{tabular}




\section{CIÊNCIAS HUMANAS}

REVISTA DO PROGRAMA DE PÓS-GRADUAĞ̈O EM EDUCAĞ̄o

\section{(10)URI|}

digitais de informação e de comunicação, pode e deve ser uma forte aliada na construção do processo de aprendizagem escolar.

Para melhor aprofundar as ideias é importante entender inicialmente o que são tecnologias? E que são tecnologias digitais? A resposta é dado por meio dos estudos de Kenski (2012) que diz que a palavra tecnologia se traduz desde os artefatos préhistóricos, como a descoberta do fogo. Ou até mesmo a invenção do lápis e da caneta por exemplo. Já as chamadas tecnologias digitais pode ser definida através dos estudos de Lopes; Monteiro, (2014) que define de forma simples que as tecnologias digitais são os dispositivos móveis, tais como a invenção do primeiro computador do celular e de tantos outros aparelhos digitais modernas, que a cada instante é lançando com um incrível grau de inteligência e capacidade para realizar inúmeras funções, que são facilitadoras para a resolução de problemas da vida cotidiana.

Nesse sentido é importante conhecer a fundo as três principiais teorias sobre as Tecnologias Digitais de Informação e de Comunicação na Educação e na aprendizagem do sujeito. Ao se tratar dessa importante temática um dos grandes precursores nessa temática é Pierre Lévy (1999). Onde é abordado que o ato de ensinar e aprender no mundo digital, é uma necessidade no mundo globalizado de hoje, onde o que tem imperado são as ferramentas tecnológicas, que estão espalhadas por todas as parte e são tão uteis para a resolução de inúmeras atividades das mais diferentes profissões.

O referido autor dá ênfase para a importância da ideia de Cibercultura. Um tema de grande relevância para o novo ensinar e o novo aprender dentro desse universo tão diversificado e rico que o mundo tecnológico digital. Um importante recurso que tem os dois lados da moeda os malefícios e os benefícios. Importante frisar que os benefícios devem superar os malefícios que a mesma pode apresentar. Assim, logo somos reportados para a fala de Kobs (2016), que diz que tecnologia é um processo veloz e continuo, que está em constantes mudanças. Tais mudanças ocorrem rapidamente que até mesmo os adeptos mais fieis têm dificuldade em manterem-se atualizados. Dessa forma o docente precisar estar atentos para todas essas importantes 


\section{CIÊNCIAS HUMANAS}

REVISTA DO PROGRAMA DE PÓS-GRADUAĞ̈O EM EDUCAĞ̄o

\section{(1) URI|}

mudanças e explorar de forma satisfatória tudo aquilo, que pode ser útil para o processo de aprendizagem desse sujeito.

Então, o processo educativo deve ser sempre ativo e dinâmico compatível para as inovações, sejam elas as digitais ou não. Todo esse leque de possiblidades, requer um cuidado e uma cautela. Porque as mudanças presentes no espaço escolar, precisam ser sempre positivas e construtivas. Assim, a escola, a família, a sociedade e os órgãos responsáveis precisar ser sábios para que aconteça o manuseio correto de todas essas ferramentas digitais.

Por outro lado, vale lembrar que fala de Moran (2007), fica explicito que só o uso das tecnologias digitais não está todas as melhores soluções. Para o processo de escolarização. É importantes, ressaltar que ensinar e aprender é um maiores desafios enfrentamos em todas as épocas. O referido autor, ainda abre um parênteses para a atual situação em que muitos ao invés de está usando todos esses aparatados tecnológicos de forma positiva. Estão na realidade reféns e pressionados pelo modelo de gestão industrial e capitalista imposto no momento,

Os estudos de (LÉVY, 1999) é amplo dentro dessa importante temática que é as tecnologias digitais da informação e da comunicação. E segundo ele, a velocidade da renovação de saberes, a nova natureza do trabalho e a amplificação, exteriorização tem sido veloz e atrativas. No entanto há muito ainda para ser estudado e repensando, quando se trata de aprendizagem escolar e digital. Porque todos esses recursos tecnológicos, nem sempre tem sido usados de forma construtiva. Onde se tem percebido que a grande maiorias das crianças, adolescentes e jovens tem usado as ferramentas digitais de forma apenas para entretenimento, ou até mesmo em coisa fúteis, que não trarão resultados satisfatório, no que se refere ao desenvolvimento científico, intelectual e social do sujeito.

A capacidade de aprendizagem do sujeito é algo extraordinário e todo esse potencial deve ser explorado de forma ampla e positiva. Uma vez que, existem inúmeras funções cognitivas do ser humano, a serem trabalhadas e desenvolvidas.

Nesse sentido a Educação no espaço da cibercultura é uma realidade inevitável, uma vez que a nova geração, que se encontra inserida dentro do espaço 


\section{CIÊNCIAS HUMANAS}

REVISTA DO PROGRAMA DE PÓS-GRADUAĞ̈O EM EDUCAĞ̄o

\section{(1) URI|}

escolar, já está habituada e ao mesmo tempo dependente e todo esses aparatos tecnológicos. E de acordo com uma pesquisa Digital realizada em 2016 são mais de 3,4 bilhões de pessoas conectadas à Internet. E parte desse número significativo, não tem usado da forma correta esse recurso tecnológico em prol do desenvolvimento de competências e habilidades que são necessárias e obrigatórias dentro do processo de escolarização.

De forma simplificado o ensino e a aprendizagem estão alicerçados dentro das chamadas "tecnologias intelectuais". Uma vez que as mesmas são muito positivas, desde que sejam manuseadas da forma correta beneficiando o acesso às informação, desenvolvendo novos estilos de raciocínio e de conhecimento, que se faz tão necessários na atualidade (LÉVY, 1999).

Em meio a era tecnológica, em todos estamos vivendo Lévy(2012) nos direciona para a chamada reformas nos sistemas de educação e formação continuada dos docentes, que se encontram em exercício de suas funções. Poque a educação pode ser dividida em dois importantes períodos antes e o depois da tecnologia digital. Como nos confirma Bagatini, (2015) houve no período da educação tradicional, que não havia toda essa riqueza e diversidade de recursos digitais. Um tempos saudoso em que, as correspondências eram enviadas via correio, os livros que eram impressos se tornaram em pdf e em poucos minutos estão espalhados na imensidão do universo virtual.

E ao falar de mudanças, que ocorreram ao longo das décadas, Schneider, (2013) explica que uma geração que envelhece hoje, é facilmente substituída por outra. Um ponto chave que o autor se refere é que a geração digital tem atropelando uns ao outros devido o fator digital, imposto pelo momento vivido na sociedade atual.

Bortolazzo,(2012), faz uma alerta acerca de todas essas tecnologias digitais que num período tão curto, tem alterado radicalmente o modo de vida nas sociedades. E o referido autor lança a seguinte interrogativa. Taus mudanças e impactos são benéfico ou nocivo? E a resposta é dado pelo mesmo autor dependente da visão e das questões filosóficas de cada um. Se olharmos com o olho da humanização as pessoas na era tecnológica perderam um pouco do está perto, de estar mais próximo um do outro, do dialogo humano e da afetividade. Se olharmos pelo lado da revolução digital ocorreu 


\section{CIÊNCIAS HUMANAS}

REVISTA DO PROGRAMA DE PÓS-GRADUAĞ̈O EM EDUCAĞ̄o

\section{(1) URI|}

inúmeras conquistas em todas as áreas e profissões do trabalho, onde todos forma em globalizados um vasto sistema de informações digitais.

As mudanças citadas por este autor denotam os impactos que as tecnologias digitais, trouxeram no contexto da sociedade acadêmica e civil. Por outro lado, a realidade da escola pública é ainda um pouco defasada, pois ainda não existe os recursos necessários em todas as escolas, e nem muito menos a estrutura apropriada para, que aconteça uma aprendizagem tecnológica digital de forma significativa. Nesse sentido governos e os órgãos responsáveis pelo sistema educacional, precisar traçar ações e intervenções na forma de políticas públicas educacionais que contemple de forma ampla e continua a aprendizagem digital contextualizada com a realidade de cada escolar, bem como em comum acordo com todas as áreas do conhecimento de forma interdisciplinar.

Favorecer de forma ampla e significativa para os nossos alunos uma aprendizagens personalizadas, coletiva e digital é sem sombras de duvidas um desafio e tanto para o sistema público de ensino na atualidade. Uma vez que se tratando de educação pública brasileira, a educação nem sempre tem sido um alvo prioritário por parte de nossos governantes em exercício. Assim (LÉVY, 1999) explica que a postura do novo professor na era digital é o de incentivador e animador da inteligência coletiva digital. Uma realidade que precisa ser trabalhada com cautela para que seja ofertada não só meras informações, e sim o direto a um conhecimento e uma aprendizagem de forma significativa.

As mídias digitais estão por toda as partes, embora não tenha ainda sido articulada para o aprender de forma significativa dentro do âmbito digital e tecnológico. Ainda usando as palavras de Lévy (2012) comenta que as ferramentas digitais para a Educação é imprescindível para o sucesso escolar. O referido autor justifica, que falta na realidade a gestão educacional prioritária para que sejam articulada ações e estratégias para que aconteça uma aprendizagem de fato digital.

Lévy (2012) explica de forma clara que as ferramentas digitais são excelentes para se trabalhar a disciplina mental do sujeito, aprende melhor a 


\section{CIÊNCIAS HUMANAS}

REVISTA DO PROGRAMA DE PÓS-GRADUAĞ̈O EM EDUCAĞ̄o

\section{(1)URI|}

concentração, é útil também para ser aplicado na resolução de problemas da vida cotidiana.

Moran é outro colaborador no requisito na Educação Inovadora. O referido autor, enfatiza também a necessidade de mudanças nos paradigmas no ensino/aprendizagem, principalmente agora com as inserções das novas TICs. Moran, (1999) ainda ressalta que ensinar com o apoio das novas mídias, significa uma revolução no sistema de ensino. E isso já é muito perceptível a todos. Há a enorme necessidade de mudarmos os paradigmas convencionais do ensino, e adotar inúmeras possibilidades para oferecer maior dinamismo e ludicidade na arte do ensinar, e obviamente que tais intervenções precisam ser subsidiadas por meios dos recursos digitais, que estão nas mãos e na realidade de todos.

Observando ainda a fala de Moran (1999) um dos problemas presente na educação atual é o distanciamento entres professores e alunos. O referido autor fala da realidade em que muitos desses professores resistem as mudanças tecnológicas, que são inevitáveis e estão sucumbidos em um mundo de metodologias ultrapassadas e o aluno da geração atual mergulhado no universo virtual. Ambos se encontram na grande maioria das vezes em mundo opostos. Moran (1999) explica de forma sucinta que a mudança deve ser significativa no que se refere a metodologia de ensino. Porque o analfabetismo digital docente é um problema atual e grave. O autor diz, que o corpo docente precisa receber um verniz de modernidade, adequando-se a necessidades e mudanças exposta na atualidade. De forma clara Moran, (1999) define a Internet como um novo meio de comunicação, ainda incipiente, porém auxiliador para ampliar e a modificar as diferentes possibilidade de ensinar e de aprender.

Moran, (2015) em sua teoria fala que a todo o tempo o ser humano aprender, seja de forma formal ou informal, e que ao logo dos anos esse processo se repete. Porque de acordo com Ausubel (2003) o sujeito é um o universo ser vivo que nasce incompleto e inacabado, sendo necessário que determinadas competências e habilidades seja desenvolvidas dentro do processo de escolarização. 


\section{CIÊNCIAS HUMANAS}

REVISTA DO PROGRAMA DE PÓS-GRADUAĞ̈O EM EDUCAĞ̄o

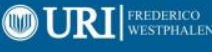

Moran (2015) com a vasta experiência que possui, afirma que é possível mudar e inovar a Educação. E esse importante processo se dá por meio do universo digital, no qual todos estão sendo passo a passo conduzidos.

As mudanças são nítidas a todos, no que se refere o novo jeito de educar, frente a interação e a mediação em sala de aula com os alunos. O professor que dentro de sua ação pedagógica, não for inovador, tecnológico e lúdico ficará sem o poder de convencimento. Porque a criança, o adolescente de o jovem de hoje, já não tem mais aquela visão de educação reprodutora do qual, muitos foram formados. A visão que se tem, é de uma educação muito mais em movimento, centrada em ações mais atrativas, curiosas e digitais, uma vez que muitos respiram todos os dias essa realidade virtual.

A Escola para ser digital, tecnológica e inovadora precisa de alguns requisitos básicos. E, é esse tipo de escola que se almeja construir, para que a mesma, seja prazerosa, lúdica, atrativa e capaz de propiciar uma aprendizagem cientifica, intelectual, cognitiva e digital também. Nesse sentido o autor revela sete importantes concepções, para tornar a educação e a aprendizagem inovadora e atual:1. Ambientes institucionais acolhedores e de incentivo à experimentação; 2. Currículos transdisciplinares, personalizados, híbridos; 3. Metodologias ativas; 4. Tecnologias digitais integradas; 5. Integração profunda com a cidade e com o mundo: aprendizagem/serviço; 6. Professores orientadores e mentores; e 7. Novas formas de avaliação e certificação (MORAN, 2013, p.1).

De forma simplificada a concepção de uma inovação educacional é o fruto do resultado de inúmeras ações e estratégias, das quais forma citadas acima. Existe diferentes formas de ensinar e aprender, inúmeras possibilidades e diferentes caminhos. E aqueles velhos métodos, que foram por anos introduzidos pela educação tradicional, já não é mais compatível com a realidade de hoje. A geração de nossas crianças, adolescentes e jovens tidos hoje como a geração elétrica e do imediatismo, não ficaram mais satisfeitas com um ensino monótono, rotineiro e desgastado.

A aprendizagem é fruto da combinação dos conhecimentos prévios com os conhecimentos científicos, que precisam estar bem casados. E na teoria de Ausubel (2003) isso ganha maior ênfase. Moran, (2015) explica que existe três tipos de 


\section{CIÊNCIAS HUMANAS}

REVISTA DO PROGRAMA DE PÓS-GRADUAĞ̈O EM EDUCAĞ̄o

\section{(1)URI|}

aprendizagem. A primeira é a individual, onde cada um pode aprender o básico por si mesmo. E ela pode acontecer também, através dos conhecimentos prévios, e por meio da aula invertida. A segunda é a aprendizagem coletiva, que ocorre por meio de diferentes atividades em grupos, dando maior ênfase para as interatividade e as relações interpessoais. A terceira é a aprendizagem mediadora, onde ocorre a intervenção de professores, orientadores, mentores (MORAN, 2015).

É importante ressaltar, que todas essas diferentes aprendizagens que ocorrem e que são construídas ao longo da vida pessoal e escolar do sujeito, requer um sentido e um significado. Dessa forma as novas tecnologias digitais vem como facilitadoras dentro desse importante processo de construção e de reconstrução de diferentes aprendizagens.

George Siemens (2004) em seus estudos uma importante fala que nos direciona para aprendizagem da Informação e da comunicação. E, isso nos lembra que as novas TICs enfatiza a questão da informação e da comunicação digital. Assim, o sujeito que está inserido dentro do processo educativo tem maior autonomia para ser um construtor individual e coletivo de sua própria aprendizagem. Ainda de acordo com Siemens (2004) as características do indivíduo tecnológico é um nível de desenvolvimento mais avançado em relação ao indivíduo que não é tecnológico.

O processo de aprendizagem digital é um processo desafiador. Porque oferece uma forma de pensar, raciocinar e assimilar informações de forma muito mais ampla. Os recursos tecnológicos disponíveis é ainda um grave problema, que precisa ser intervindo. Há uma necessidade de definir, moldar e organizar um novo padrão para educar e ensinar de forma significativa e digital.

Analisando a fala de Siemens (2004), o contexto atual educacional precisa está atento para os impactos da tecnologia. Porque ele tem sido um instrumento usado também para articular o mau. No sentido de destruir a infância, a inocência e a pureza de nossas crianças. Roubando o tempo para a realização de jogos e brincadeiras presenciais ao lado de outras crianças da mesma idade e nível de aprendizagens. Um período importante na vida do indivíduo que precisa ser vivenciado com intensidade e felicidade. Tais impactos precisar ser cuidadosamente trabalhados para que a infância e 


\section{CIÊNCIAS HUMANAS}

REVISTA DO PROGRAMA DE PÓS-GRADUAĞ̈O EM EDUCAĞ̄o

\section{(1) URI|}

a adolescência, não sejam vitimadas por jogos eletrônicos perigosos, que tem levado a muitos a morte, dependência tecnológica, isolamento social e tantos outros problemas dessa natureza.

Explorando ainda da fala de Siemens (2004), um dos defensores do Conectivismo, uma importante teoria ao se abordar as abordagens da novas TICs, define de forma clara que a aprendizagem é um processo de conectar a informação cientifica com os conhecimentos prévios desse sujeito. Essa importante transição deve ocorrer com cuidado e de forma simultânea.

As ferramentas digitais são importantes recursos para possibilitar a criação de novos ambiente educativo, muito mais propicio para o ensino-aprendizagem de forma ampla e significativa. O leque de possiblidades para uma educação tecnológica e digital são inúmeras. Uma delas é o uso de vários softwares e aplicativos educacionais, que podem ser instalados nos computadores, tablets, notebooks ou em smartphones, em prol de uma aprendizagem digital de maior acesso e de maior alcance para todos.

A ferramenta digital, é um ponto de discussão da UNESCO (2015) que vem desenvolvendo políticas públicas educacionais para combater a exclusão digital, que é ainda um problema a ser intervindo. E ainda de acordo com a UNESCO (2015) a Aprendizagem deve ser móvel. É definida como uma das soluções para transformar positivamente a educação e a aprendizagem que temos na atualidade. Propiciando a construção de uma educação equitativa e de qualidade para todos. A própria (UNESCO) enxerga que as ferramentas digitais e o uso correto das mesmas, podem ser um recurso amenizador para sanar alguns problemas presentes na educação atual.

David Cavallo, com sua vasta experiência em educação e tecnologia, afirma que é impossível oferecer uma educação de qualidade, sem a participação ativa e continua dos aparatos tecnológicos.

\section{CONSIDERAÇÕES FINAIS}

Os resultados do artigo trouxeram respostas satisfatórias acerca da relevância das novas tecnologias digitais, em prol da aprendizagem dos sujeitos. É

\begin{tabular}{l|l|l} 
Recebido em: 10/04/2019 & Aceito em: 28/04/2019 & Pg. 115 - 129
\end{tabular}




\section{CIÊNCIAS HUMANAS}

REVISTA DO PROGRAMA DE PÓS-GRADUAĞ̈O EM EDUCAĞ̄o

\section{(1) URI|}

evidente também que há a necessidade de inúmeras reflexões e reajustes no que se refere a aprendizagem digital, no sistema educacional, principalmente no requisito aprendizagem.

Em constatação foi possível perceber que as novas ferramentas digitais são recursos relevantes em prol da resolução de problemas presentes no sistema de ensino. E que por meio dos diferentes ambientes virtuais, as aulas podem se tornar muito mais atrativas e dinâmicas, oferecendo momento de aprendizagens diversificados e significativos.

Por meio desse artigo, pode se constatar que o sujeito da geração atual é mais do que tecnológico, e que a escola cada vez amis deve ser empreendedora no requisito renovação para atender as grandes demandas, que são oferecidas no mundo globalizada aprendizagem não pode deixar lacunas. Dessa forma a aprendizagem que é construída deve possuir caráter significativo sempre, sendo acima de efetivo e útil para a resolução de problemas e a tomada de decisões.

As tecnologias digitais é algo extraordinário e que pode e deve ser usado de forma benéfica na educação em várias instâncias, para uma ampla aprendizagem dentro das mais diversas áreas do conhecimentos. Pode se observar a carência de muitas escolas, em específicas as mais pobres a falta de uma estrutura para as sala de laboratórios, que permitam o acesso e a pesquisa educacional, incentivando o uso correto de tais tecnologias, em prol de uma desenvolvimento cientifico muito mais amplo. Por outro lado o analfabetismo digital, por parte de muitos docentes é ainda um grave problema a ser intervindo.

As tecnologias digitais inseridas nas sala de aula serão capazes de propiciar uma melhor interação com seus alunos e professores, auxiliando para que aprendizagem ganhe mais sentido e significado. Nos dias de hoje para se construir uma educação do futuro e para o futuro é necessário preparar professores que ensinem voltados para essa grande dimensão das TICs, focados na aprendizagem efetiva e digital de seus alunos.

É necessário ainda um olhar cuidadoso sobre os riscos e perigos que todos esses aparatos tecnológicos podem oferecer aos alunos.Com foi citado anteriormente há os benefícios e malefícios. Novos métodos e estratégias devem ser a cada dia articulado 


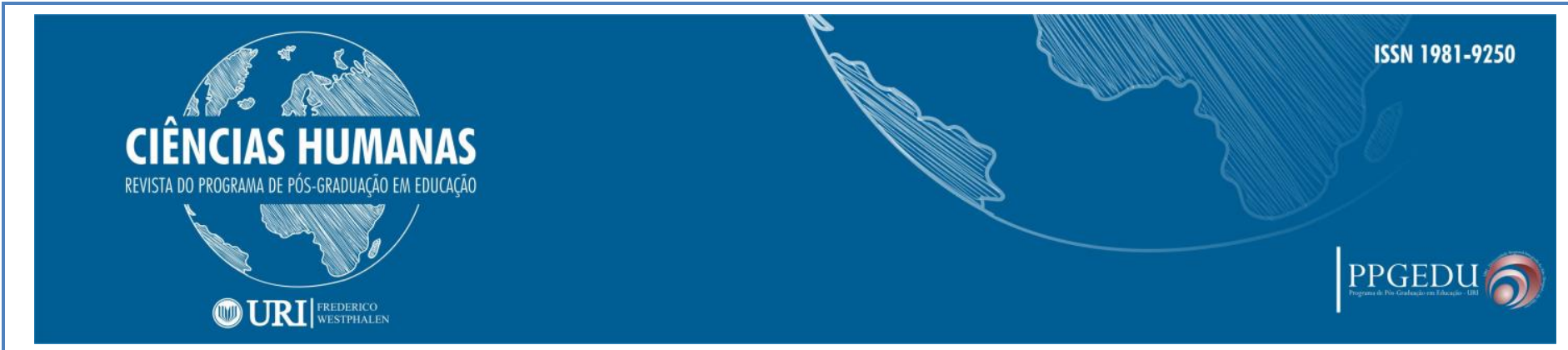

para que a cada momento de escolarização aconteçam construções concretas e ampla dentro do ensino e da aprendizagem do aluno de hoje.

Obviamente que os problemas sempre existiram, mas todos eles devem ser explorados e intervindos na busca por ações e soluções que os amenizem. E como diz o teórico Moran(2007) para aprender de forma significativa depende de inúmeras ações tais como a motivação, o foco e o uso correto das metodologias acompanhado de atitudes concretas.

\section{REFERÊNCIAS}

BAGATINI, Fabrício Agostinho. Tessituras da docência em tempos de tecnologias de informação e comunicação. 2015. 337 f. Dissertação (Mestrado em Ensino) - Centro Universitário UNIVATES, Lajeado, 24 jul. 2015.

BORTOLAZZO, Sandro Faccin. Nascidos na era digital: outros sujeitos, outra geração. In: XVI ENDIPE - ENCONTRO NACIONAL DE DIDÁTICA E PRÁTICAS DE ENSINO, 2012, Campinas. Anais.... Campinas: UNICAMP, 2012.

CASTRO, Mariela. Estou conectado, logo existo. 09 jan. 2013. Disponível em: Acesso em: 01 nov. 2018.

COMITÊ Gestor da Internet no Brasil. TIC Educação 2015. Pesquisa sobre o uso das tecnologias de informação e comunicação nas escolas brasileiras. São Paulo: Comitê Gestor da Internet no Brasil, 2016a.

KENSKI, Vani Moreira. Educação e tecnologias: o novo ritmo da informação. 8. ed. Campinas, SP: Papirus, 2012.

KOBS, Fabio Fernando; CASAGRANDE JUNIOR, Eloy Fassi. O papel das tecnologias digitais na educação: perspectivas para além dos muros da escola. Rev. Cienc. Educ., Americana, ano XVIII, n. 34, p. 41-73, jan./jun. 2016.

LÉVY, P. Cibercultura. São Paulo: Editora 34, 1999.

LEVY, P. Só tablets não fazem trabalho sozinhos. [Entrevista cedida a] Bruno Alfano. Extra, Rio de Janeiro, 03 ago. 2014. Geral, p.15. Disponível em: Acesso em: 10 maio 2017.

LÉVY, P. Internet e escola de mãos dadas: entrevista com Pierre Lévy. Gestão Educacional, Curitiba, jul. 2012. Disponível em:Acesso em: 11 jul. 2018.

\begin{tabular}{l|l|l} 
Recebido em: 10/04/2019 & Aceito em: 28/04/2019 & Pg. 115 - 129
\end{tabular}


LOPES, Ana Helena Ribeiro Garcia de Paiva; MONTEIRO, Maria Iolanda; MILL, Daniel Ribeiro Silva. Tecnologias Digitais no contexto escolar: Um estudo bibliométrico sobre seus usos, suas potencialidades e fragilidades. Revista Eletrônica de Educação, v. 8, n. 2, p. 30-43, 2014.

MORAN, J.M. Educação híbrida: o futuro para a aprendizagem. [Entrevista cedida a] Andréa Antunes. São Paulo, 2015. [Blog de Palestras, Workshops, Cursos]. Disponível em: \# Tear: Revista de Educação Ciência e Tecnologia, Canoas, v.7, n.2, 2018. 16 . Acesso em: 30 maio 2017.

MORAN, José Manuel. Aprendendo integralmente por desafios. 2013a. Disponível em: $<$ http://moran10.blogspot.com.br/2013_10_01_archive.html> Acesso em: 06 nov. 2016.

MORAN, J.M. Principais diferenciais das escolas mais inovadoras. São Paulo, 2013. [Blog de Palestras, Workshops, Cursos]. Disponível em: . Acesso em: 11 jul. 2018.

MORAN, J.M. O uso das novas tecnologias da informação e da comunicação na EAD: uma leitura crítica dos meios. Belo Horizonte: [s.n.], 1999. [Palestra proferida pelo Professor José Manuel Moran no evento "Programa TV Escola - Capacitação de Gerentes", realizado pela COPEAD/SEED/MEC em Belo Horizonte e Fortaleza, no ano de 1999]. Disponível em: . Acesso em: 11 jul. 2018a.

MORAN, J.M. Ensino e aprendizagem inovadores com apoio de tecnologias. In: MORAN, J.M.; MASETTO, M. T.; BEHRENS, M.A. Novas tecnologias e mediação pedagógica. 21. Ed. rev. atual. São Paulo: Papirus, 2015a. p. 11-72.

SIEMENS, G. Conectivismo: uma teoria de aprendizagem para a idade digital. [S.l.: s.n.], 2004. Disponível em: . Acesso em: 24 abr.2017. TECNOLOGIA e inovação em aula é tema de debate do Educação 360. O Globo, Rio de janeiro, 24 jan. 2016. Disponível em: . Acesso em: 24 abr. 2017.

SCHNEIDER, Dado. O mundo mudou... bem na minha vez! 3. ed. São Paulo: Integrare Editora, 2013.

UNESCO. Representação da UNESCO no Brasil. Aprendizagem móvel. Brasília, [201?]. Disponível em: < http://www.unesco.org/new/pt/brasilia/communicationandinformation/access-to-knowledge/ict-in-education/mobile-learning/>. Acesso em: 12 maio 2017.

UNESCO. Representação da UNESCO no Brasil. Relatório de Monitoramento Global de EPT 2015 [Programa Educação para Todos 2015]. Brasília, [201-?]a. Disponível em: . Acesso em: 12 maio 2017a. UNESCO. Representação da UNESCO no Brasil. TI na Educação do Brasil. Brasília, [201- ?]b. Disponível em: . Acesso em: 15 maio 2018b.

\begin{tabular}{l|l|l} 
Recebido em: 10/04/2019 & Aceito em: 28/04/2019 & Pg. 115 - 129
\end{tabular}




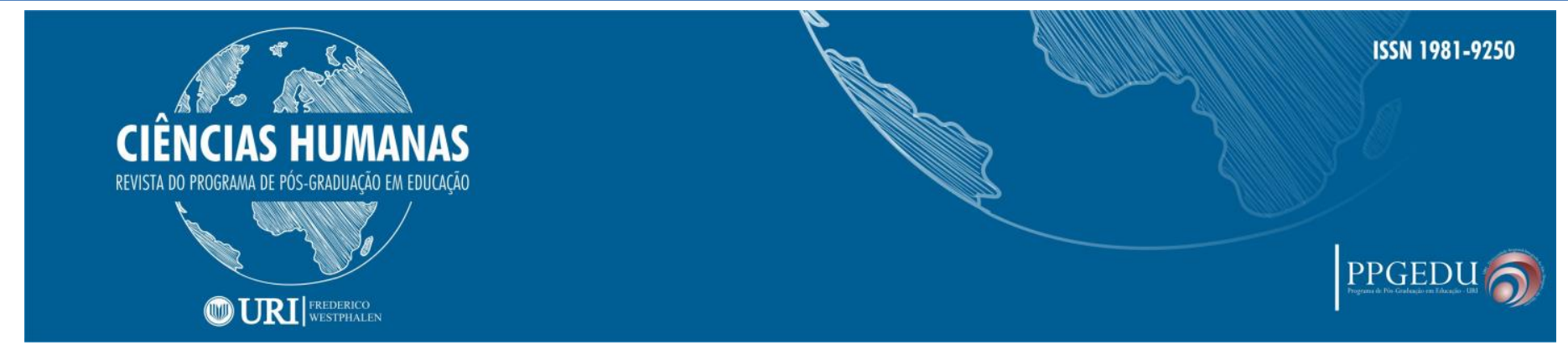

UNESCO. Representação da UNESCO no Brasil. Aprendizagem móvel. Brasília, [201?]. Disponível em: < http://www.unesco.org/new/pt/brasilia/communicationandinformation/access-to-knowledge/ict-in-education/mobile-learning/> . Acesso em: 12 maio 2017.

UNESCO. Representação da UNESCO no Brasil. Relatório de Monitoramento Global de EPT 2015 [Programa Educação para Todos 2015]. Brasília, [201-?]a. Disponível em: . Acesso em: 12 maio 2017a.

UNESCO. Representação da UNESCO no Brasil. TI na Educação do Brasil. Brasília, [201- ?]b. Disponível em: . Acesso em: 15 maio 2017b. \# Tear: Revista de Educação Ciência e Tecnologia, Canoas, v.7, n.2, 2018. 